\title{
Utilização do fórum como ferramenta colaborativa na EaD
}

\author{
Artur Nobre Silva ${ }^{1}$, Danieli Silva de Souza Rabelo ${ }^{1}$, Isabel Dillmann Nunes ${ }^{2}$, Juliana \\ Lacerda da Silva Oliveira ${ }^{1}$, Maria Cristina Leandro de Paiva ${ }^{3}$, Stênio Lúcio da \\ Rocha $^{1}$
}

${ }^{1}$ PPgITE - Programa de Pós-Graduação em Inovação em Tecnologias Educacionais. Universidade Federal do Rio Grande do Norte-UFRN- Natal - RN - Brasil

2Instituto Metrópole Digital - IMD-UFRN- Natal - RN - Brasil

${ }^{3}$ Departamento de Fundamentos e Políticas da Educação- Centro de EducaçãoDFPE-CE-UFRN-Natal - RN- Brasil

\footnotetext{
\{arturnobres@gmail.com, rabrlodanni@gmail.com, bel@imd.ufrn.br, julacerda01@gmail.com, crislean6@gmail.com, steniolucio1305@gmail.com\}
}

\begin{abstract}
The forum activity in its nature is mostly presented as a collaborative teaching tool to present / discuss the content of the course, in which students contribute their difficulties and expectations regarding the material provided by the teacher. The study aimed to investigate collaboration and learning in the use of the Moodle platform forum, evaluating users' experiences to promote collaborative learning. The research took place in two stages: first, bibliographical review of the concepts; and second, the application and analysis of semi-structured questionnaires and showed that both teachers and students consider the forum a motivational tool capable of promoting learning.
\end{abstract}

Resumo. A atividade fórum em sua natureza apresenta-se em sua maioria como ferramenta de ensino colaborativa de apresentação/discussão do conteúdo do curso, em que os alunos contribuem com suas dificuldades e expectativa em relação ao material disposto pelo professor. O estudo objetivou investigar a colaboração e a aprendizagem no uso do fórum da plataforma Moodle, avaliando as experiências dos usuários para promover uma aprendizagem colaborativa. A pesquisa ocorreu em duas etapas: primeiro, revisão bibliográfica dos conceitos; e, segundo, aplicação e análise de questionários semiestruturados e mostrou que tanto docentes quanto discentes consideram o fórum uma ferramenta motivacional capaz de promover a aprendizagem.

\section{Introdução}

A educação vem passando por mudanças necessárias em suas metodologias de ensino, que proporcionam aos alunos aprendizagens, atribuição de sentido e significado aos conteúdos correlacionando-os com diversos segmentos. Muitos professores têm buscado utilizar metodologias nas quais o aluno seja o centro do processo e produtor do conhecimento. Quando se fala em Educação a Distância ou Ambientes Virtuais de Aprendizagem, temos a possibilidade das dimensões da sala de aula ampliadas em tempos e espaços diversos, o aluno passa a interagir diretamente com uma máquina e seus colegas de sala e professor distantes, porém conectados. Para esse modelo de ensino, o engajamento e a motivação são os grandes entraves enfrentados pelos professores, pois, 
VII Congresso Brasileiro de Informática na Educação (CBIE 2018)

Anais do XXIV Workshop de Informática na Escola (WIE 2018)

como os alunos estão em contato direto com o computador, faz-se necessário pensar em estratégias que possam envolver o aluno no processo de aprendizagem no qual possa interagir, compartilhar e colaborar.

Nessa discussão, apresentamos como desafio a promoção dessa aprendizagem nos Fóruns de discussão do Ambiente Virtual de Aprendizagem Moodle Mandacaru que propiciam ao professor acompanhar o desenvolvimento de seus alunos, interagir com eles e também fazer suas intervenções.

Diante desse contexto, surgiu a seguinte problemática: qual a concepção dos professores e discentes sobre o uso da Ferramenta Fórum em EaD para promover um espaço de aprendizagem colaborativa? Dessa maneira, objetivo geral desta pesquisa é investigar a colaboração e a aprendizagem no uso do fórum da plataforma moodle Mandacaru, avaliando as experiências dos usuários na promoção de uma aprendizagem colaborativa. Para isso, realizamos uma pesquisa qualitativa e quantitativa com docentes e discentes de diversos cursos e turmas do semestre 2018.1, que fazem uso da nova versão do Moodle.

Os resultados apresentados apontam para um cenário no qual o uso da ferramenta fórum precisa ser repensada de forma a dinamizar e contribuir no processo de ensino e aprendizagem dos alunos da Educação a Distância.

O presente trabalho está distribuído da seguinte forma: 1. Introdução; 2. Fundamentação Teórica; 2.1 Fatores motivacionais da aprendizagem; $2.2 \mathrm{O}$ uso do Fórum como ferramenta colaborativa; 3 Metodologia; 4 Resultados e Discussões; 5 Conclusões.

\section{Fundamentação teórica}

Trata-se, nesse tópico, os pressupostos teóricos que permitem realizar reflexões sobre a temática da pesquisa, visando a apropriação e a contextualização, preliminarmente, aos objetivos propostos no estudo em questão. Dessa maneira, discute-se o aporte teórico deste trabalho por um diálogo sobre fatores motivacionais da Aprendizagem e, posteriormente, uma breve discussão sobre o uso do fórum como ferramenta colaborativa na $\mathrm{EaD}$.

\subsection{Sobre fatores motivacionais da Aprendizagem}

De acordo com Soares et al. (2016), existem vários fatores, dentre eles motivacionais, que podem dificultar e até mesmo anular a inserção da tecnologia e o uso de suas ferramentas no ambiente educacional e consequentemente o ensino e a aprendizagem. Sua pesquisa buscou investigar e analisar tais fatores no uso de softwares, hardwares e sistemas computacionais.

Dentre os fatores intrínsecos que mais se impulsionam o ensino/aprendizagem a distância ou semipresencial, destaca-se neste trabalho a motivação para a aprendizagem. Este é um elemento fundamental e que coopera significativamente para o entendimento dos conteúdos propostos.

De acordo com a teoria de Robert Gagné (1980), a aprendizagem é uma mudança de estado interior que se manifesta por meio da mudança de comportamento e na persistência dessa mudança. Um observador externo pode reconhecer que houve aprendizagem quando percebe a ocorrência de uma mudança comportamental e também a permanência desta. Trata-se, portanto, de uma mudança comportamental persistente em que as mudanças resultantes do desenvolvimento de estruturas internas constituem-se na maturação, ou seja, a própria aprendizagem. Segundo ele, isso ocorre quando o indivíduo recebe estímulos externos e o processo de maturação do conhecimento permite seu 
crescimento interno. Este pesquisador da aprendizagem postula também sobre vários tipos de estimulação provenientes do ambiente onde se encontra o indivíduo, a qual se constitui em insumo (input) aos processos de aprendizagem. Já exsumo (output) é uma modificação do comportamento que é observada como um desempenho humano.

Gagné (1980), diferentemente da abordagem behaviorista de Skinner - que se preocupa com os processos intermediários- focaliza o processo da aprendizagem. Para ele, a aprendizagem se realiza "dentro da cabeça" do aprendiz, além de destacar a importância das teorias de aprendizagem, ressaltando a chamada "teoria de processamento da informação", apresentando e discutindo um modelo básico de aprendizagem e memória como consequência de teorias de processamento de informação.

Atos de aprendizagem são precedidos, segundo Gagné (1980), por uma série típica de eventos. A aprendizagem se dá por meio de oito fases, cada uma com um nome e que identifica o processo interno envolvido na mesma. As fases são: motivação, apreensão, aquisição, retenção, rememoração, generalização, desempenho e retroalimentação.

Gagné (1980) propõe que existem cinco principais classes de capacidades humanas, as quais podem ser aprendidas: informação verbal, habilidades intelectuais, estratégias cognitivas, atitudes e habilidades motoras, enfatizando, em sua proposta, a habilidade intelectual. Nesta teoria, as habilidades mais simples que representam os "pré-requisitos imediatos" podem ser analisadas para identificar habilidades ainda mais simples, o que aponta serem tais habilidades hierarquizadas.

Com relação à instrução e ao papel do professor, por se tratar de uma teoria que prevê mudança comportamental persistente, a fase da aprendizagem existe de um ou mais processos internos, no sistema nervoso central do aluno, que transformam a informação até que o aprendiz responda com um desempenho. Tais processos internos podem ser influenciados por eventos externos, por estimulação do ambiente do indivíduo. Nessa perspectiva, a instrução é atividade de planejamento e execução de eventos externos à aprendizagem, com a finalidade de influenciar os processos internos para atingir determinados objetivos. Os objetivos são as capacidades a ser aprendidas, descrições verbais daquilo que deve ser aprendido.

A partir da descrição das condições que favorecem a aprendizagem postuladas por Gagné, cabe ao docente a tarefa de selecionar os meios apropriados a fim de promover a aprendizagem por meio da instrução, planejando, administrando e avaliando quanto à sua eficácia por meio da avaliação da aprendizagem do estudante.

Da teoria multimídia de aprendizagem do professor da Universidade da Califórnia Richard Mayer (2014), que postula saberes fazendo uma intersecção entre cognição, instrução e tecnologia. Partilhamos a ideia de que as pessoas aprofundam mais os seus conhecimentos a partir de imagens e palavras juntas do que apenas com palavras isoladas. "Palavra", nesse contexto, não se refere somente a textos impressos, mas abrange também toda mídia escrita ou falada; "imagens", por sua vez, abrange toda mídia gráfica, como vídeos, animações, jogos e ilustrações. Assim, a instrução multimídia refere-se ao modo de apresentação das palavras e imagens que se destinam a promover a aprendizagem.

O modelo proposto por Mayer(2014), revela como imagens e palavras são assimiladas através de uma apresentação multimídia, entrando na memória sensorial através da audição e visão, fatores de percepção preponderantes no ensino a distância através dos Ambientes Virtuais de Aprendizagem e das ferramentas neles 
VII Congresso Brasileiro de Informática na Educação (CBIE 2018)

Anais do XXIV Workshop de Informática na Escola (WIE 2018)

disponibilizadas para a promoção do ensino. A importância do fator visual para motivação na aprendizagem é notória nesta modalidade de ensino, o que requer estratégias diferenciadas e inovadoras para o alcance deste objetivo.

Dentre as ferramentas utilizadas neste contexto, destaca-se a do "Fórum", que permite diversas possibilidades de interação na promoção do conhecimento. Porém, ainda pouco utilizada em sua devida potencialidade.

\subsection{O uso do fórum como ferramenta colaborativa na EaD}

A ferramenta fórum é considerada, no âmbito do ensino a distância um poderoso meio de comunicação, que em sua maioria utiliza-se para implementar discussões entre seus participantes.

Levy (2001) apud Paula (2009, p. 49-50) aponta que:

[...] a virtualização de um ambiente social consiste em desenvolver ferramentas relacionadas a elaboração e compartilhamento de informação entre pessoas de uma coletividade que se tornam não presentes, se desterritorializam. A virtualização apresenta possibilidades de flexibilidade do aqui e agora. A sincronização substitui a unidade de lugar e a interconexão, a unidade de tempo. As possibilidades de comunicação e interação no ambiente virtual dependem dos atores envolvidos e de suas relações com as ferramentas tecnológicas, principalmente as de internet.

A Aprendizagem Colaborativa com Suporte Computacional (ACSC), segundo Stahl, Koschmann e Suthers (2006) tem sua ascensão nos anos 1990 e emergem das ciências da aprendizagem preocupadas em entender como as pessoas podem aprender com ajuda do computador. Para esses autores, a aprendizagem a distância permeada pela colaboração e a mediação do computador incentiva os alunos a aprenderem juntos e dessa forma também ampliarem seus conhecimentos. Neste contexto, o fórum é uma ferramenta utilizada nos Ambientes Virtuais de Aprendizagem (AVA) que possibilita, através do uso planejado e adequado, momentos de discussões, divulgação de notícias, sanar dúvidas, além disso, construir aprendizagens, em um ciberespaço que pode ser adotado pelos professores e tutores como espaço para avaliação colaborativa.

Esse processo colaborativo proporciona aos alunos expressarem suas ideias, anseios, dificuldades, proporcionando aprimorar e ampliar essa nova característica vigente no mundo, diversos são os espaços desenvolvidos e discutidos para fomentar práticas colaborativas para a aprendizagem. Nesse contexto, é importante destacar que na aprendizagem colaborativa os sujeitos aprendem juntos e, portanto, o fórum proporciona a construção colaborativa de seus aprendizados e amplia a interação. Nesse conceito de aprendizagem, o professor está dentro do processo, sendo mais um colaborador favorecendo a troca de experiências e conhecimento.

No processo de ensino a distância, é necessário motivar continuamente os alunos para que estejam dispostos a interagir entre eles e não apenas postar a sua atividade. $\mathrm{Na}$ ACSC o professor tem muito mais trabalho, pois, precisa estimular e sustentar a interação produtiva do aluno o que é difícil de alcançar, exigindo planejamento, coordenação e implementação de currículo, pedagogia e tecnologia (STAHL, KOSCHMANN E SUTHERS, 2006). O professor necessita compreender seu papel e desenvolvê-lo adotando novas posturas, aproximando os aprendizes promovendo de forma ativa novas possibilidades de ensino e aprendizagem. 
VII Congresso Brasileiro de Informática na Educação (CBIE 2018)

Anais do XXIV Workshop de Informática na Escola (WIE 2018)

\section{Metodologia}

Uma pesquisa, necessita que suas ações e etapas sejam definidas através do planejamento de seu processo. No planejamento, estabelece-se a formulação do problema, os objetivos e a operacionalização dos conceitos etc (GIL, 2002).

Neste sentido, a definição da metodologia adequada para atingir os objetivos traçados é uma fase fundamental. Tendo a presente pesquisa como objetivo, investigar a colaboração e a aprendizagem no uso do fórum da plataforma moodle, avaliando as experiências dos usuários para promover uma aprendizagem colaborativa, optou-se por um estudo qualitativo e quantitativo além de um estudo de caso. Destarte, o estudo delineia-se em uma abordagem qualitativa e quantitativa, pois, segundo Malhotra (2001, p.155), "a pesquisa qualitativa proporciona uma melhor visão e compreensão do contexto do problema, enquanto a pesquisa quantitativa procura quantificar os dados e aplica alguma forma da análise estatística".

O desenvolvimento da pesquisa aconteceu em duas etapas de formas concomitante: primeiro, revisão bibliográfica dos conceitos que fundamentam o estudo; e, segundo, aplicação e análise de questionários semiestruturados.

No sentido de entender como acontece a colaboração no fórum de discussão e como esta contribui para a aprendizagem, aplicou-se um questionário contendo 5 perguntas, sendo quatro objetivas e uma subjetiva, para alunos e professores. Por meio da ferramenta do formulário do google, elaboramos os questionários que foram enviados por e-mail para 149 estudantes $^{1}$ da disciplina Profissão Docente e 132 professores $^{2}$ de diversas turmas de cursos à distância da Universidade Federal do Rio Grande do Norte-UFRN. É importante destacar que, como parte da pesquisa, também foi anexado um Termo de Compromisso Livre e Esclarecido (TCLE), contendo informações importantes sobre o propósito do trabalho, onde o pesquisado foi convidado a espontaneamente contribuir. Posteriormente aos envios, foram recebidos os questionários respondidos por estudantes e professores. Durante o período de aplicação, mesmo com o auxílio de recursos digitais, ocorreram dificuldades para o recebimento de um feedback mais expressivo por parte de alguns professores e alunos.

\section{Resultados e Discussões}

Neste tópico, apresentamos o questionário aplicado aos docentes que estão ministrando disciplinas em todos os 11 cursos de graduação EaD do semestre 2018.1 da UFRN. Seguidamente são enumeradas as questões e gráficos estatísticos que foram aplicados aos docentes e discentes no sentido de entender um pouco sobre o uso do fórum para construção da aprendizagem colaborativa.

\subsection{Pesquisa Aplicada aos Docentes}

$\mathrm{O}$ primeiro questionamento, conforme mostram figuras 1 e 2 , busca investigar a frequência com que os docentes utilizam o fórum nas suas atividades do semestre na modalidade à distância. Dessa maneira, obtemos os seguintes resultados:

${ }^{1}$ Questionário destinado aos discentes: https://docs.google.com/forms/d/17hfy0175LIBCl1Kc6PJaEbMcOCg-253BUV-eDGYMBDs/edit

${ }^{2}$ Questionário destinado aos docentes:

https://docs.google.com/forms/d/1qPXf_MeiV56e-ZnFrY8QmnaSNKJOpmLL4wM1aMSeT1//edit 
VII Congresso Brasileiro de Informática na Educação (CBIE 2018)

Anais do XXIV Workshop de Informática na Escola (WIE 2018)

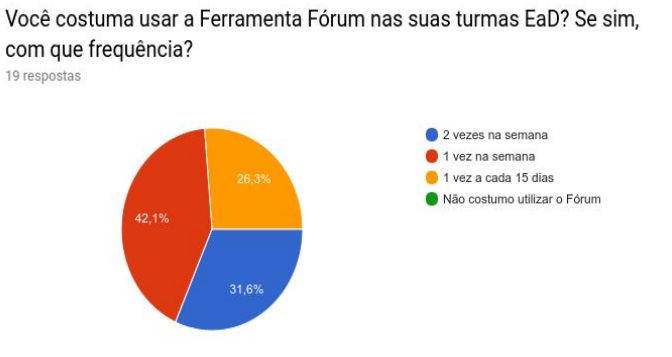

Figura 1: Resposta 1- Questionário Docente

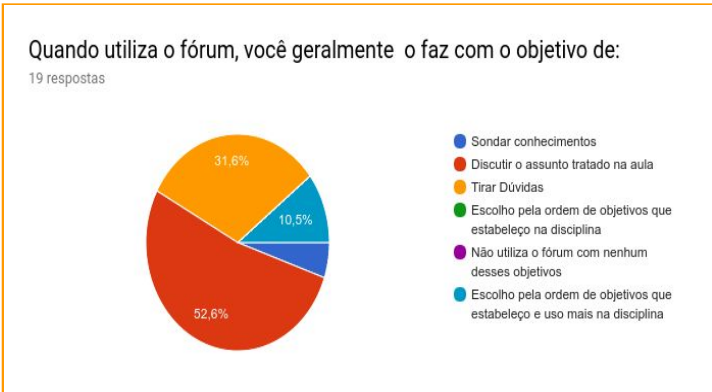

Figura 2: Resposta 2- Questionário Docente

O gráfico apresentado, na Figura 1, indica que 42,1\% dos professores fazem uso desse recurso dentro do ambiente virtual pelo menos uma vez por semana, contudo, $26,3 \%$ só usam o fórum a cada 15 dias. Esse período ausente pode contribuir para distanciamento da interação professor $\mathrm{x}$ aluno no ambiente.

O segundo questionamento,da Figura 2, aborda objetivos e ações que os docentes destinam para o uso do fórum.é notório pelos indicadores da pesquisa que, 52,6\% dos docentes utilizam objetivando debater os assuntos tratados nas aulas a fim de promover a aprendizagem por meio da interação da turma. Enquanto que, 31,6\% utilizam apenas para sanar possíveis dúvidas. Seguidamente, percebe-se pelos índices que apenas $10 \%$ dos docentes utiliza a ferramenta fórum com objetivos específicos, delineados e programados de aprendizagem. Esta ação normalmente é identificada em educação à distância como "Fórum Temático", por exemplo. A opção "Não utiliza o fórum com nenhum dos objetivos anteriores", que, vale ressaltar, não foi selecionado por nenhum dos docentes pesquisados.

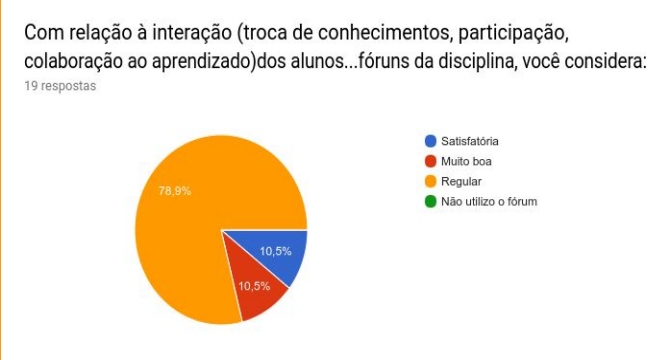

Figura 3: Resposta 3-Questionário Docente

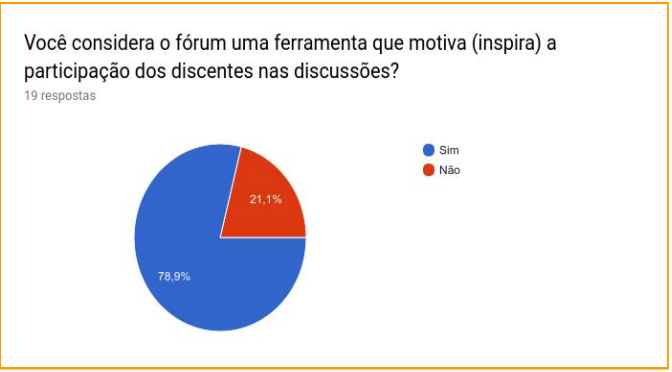

Figura 4: Resposta 4- Questionário Docente

Considerando interação o processo de troca de conhecimentos, participação e colaboração ao aprendizado, a terceira pergunta feita ao corpo docente alcançado, foi acerca de como ele classifica a interação dos alunos nos fóruns promovidos em sua disciplina. Com base nas respostas dos docentes, expostas na figura 3, para 78,9\% dos docentes a interação acontece de maneira irregular, esse índice, demonstra a necessidade de ações transformadoras e a reestruturação para uso da ferramenta, almejando efetivamente um espaço de conhecimento colaborativo, que instigue a participação e compartilhamentos de informações.

Assim, com a motivação de investigar a compreensão dos professores sobre a concepção em relação ao fórum como ferramenta que incentiva a participação dos discentes, surgiu o questionamento da figura 4: Você considera o fórum uma ferramenta que motiva, inspira a participação dos discentes nas discussões? 
VII Congresso Brasileiro de Informática na Educação (CBIE 2018)

Anais do XXIV Workshop de Informática na Escola (WIE 2018)

Nota-se, na figura 4, que 78,9\% considera o fórum com um ambiente motivador para a participação do aluno. No entanto, $21,1 \%$ não acreditam nesse fator inspirador do fórum. Esse dado é, de fato alarmante e faz um link com a pesquisa de Rabelo et al. (2017) que após processo de aplicação de técnicas de mineração de dados educacionais e análise de indicadores principais, em turmas diferentes de um semestre letivo na mesma plataforma, constatou que um dos indicadores que mais cooperam para a aprovação do discente é a interação e utilização do fórum como ferramenta colaborativa de aprendizagem.

\subsection{Pesquisa Aplicada aos Discentes}

O segundo questionário, dessa vez aplicado aos discentes, possui perguntas relacionadas a opinião dos participantes quanto a utilização, contribuição e participação dos alunos com a ferramenta fórum, como também sobre um possível conhecimento com relação ao tema abordado.

Sobre a participação, apresentado na figura 5, cerca de $40 \%$ responderam que acessam pelo menos 2 vezes na semana, 33,3\% indicaram 1 vez na semana, ainda constando uma vez a cada 15 dias e não costuma utilizar o fórum ambos resultaram em $13,3 \%$ dos alunos.

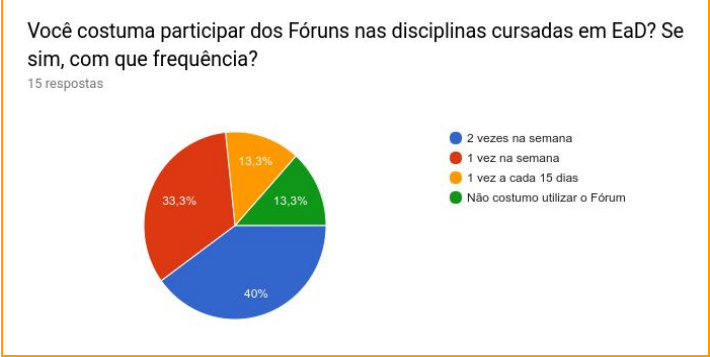

Figura 5: Resposta 1 - Questionário Discente Figura 6: Resposta 2- Questionário Discente

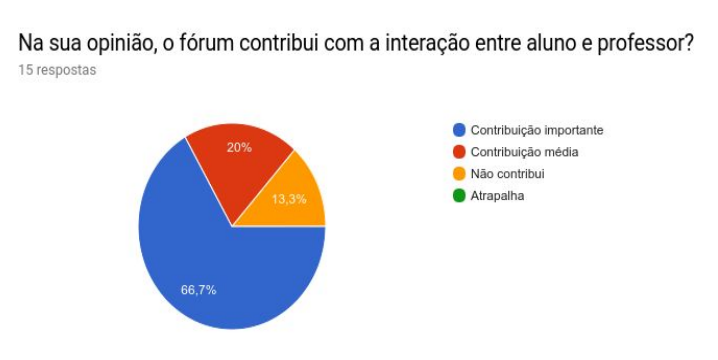

Percebe-se na figura 6, que das 15 respostas obtidas, 66,7\% opinaram que o fórum tem uma relação importante para a interação entre aluno e professor, não menos relevante, $20 \%$ dos alunos argumentaram existir uma contribuição média e 13,3\% não relaciona ou não vislumbra que o fórum contribua com o mínimo de interação entre os envolvidos. Embora as interações observadas no ambiente virtual estejam longe do ideal para a interação e a participação dos professores e alunos. Segundo Shlemer e Garrido, (2009, p. 178) "a aprendizagem em espaços coletivos, como os fóruns de discussão, pode ser gerada por movimentos de cooperação e/ou colaboração."

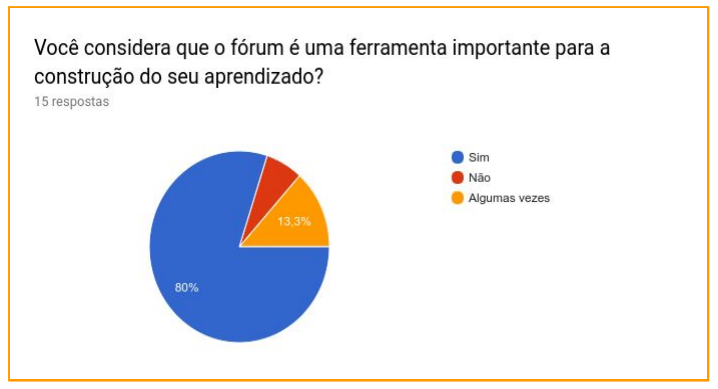

Figura 7: Resposta 3 - Questionário Discente

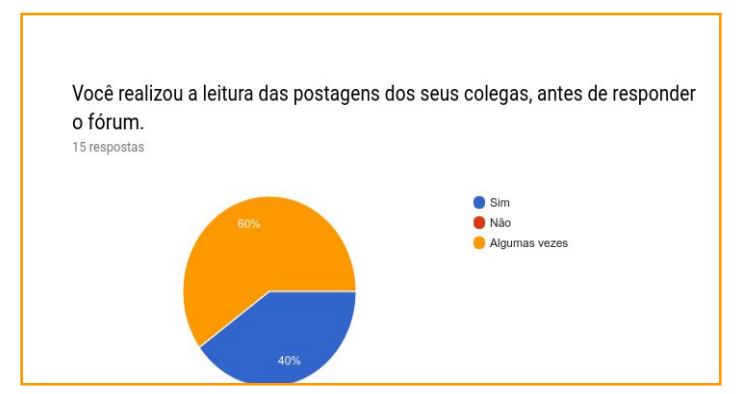

Figura 8: Resposta 4- Questionário Discente 
Em linhas gerais, na figura 7, os alunos notam a relevância do fórum com ferramenta que favorece a aquisição do conhecimento, pois apenas $6,7 \%$ dos discentes assinalaram a opção "não" enquanto $80 \%$ assinalaram que sim, indicando para um consciência e valorização da ferramenta na construção do seu aprendizado em grande parte dos alunos pesquisados.

O resultado da figura 8 , desperta para uma prática importante na colaboração/participação do aluno dentro da atividade fórum, esse procedimento se dá pela interação do aluno com os demais discentes da sua turma. Um dos primeiros passos a serem realizados no processo de interação é a realização da leitura das orientações do professor e das postagens dos colegas. Esse espaço em sua essência mostra uma movimentação em busca de um entendimento mútuo. $\mathrm{O}$ resultado desse gráfico indica que $60 \%$ dos alunos não costumam realizar a leitura das postagens dos colegas, antes de contribuir com a atividade e $40 \%$ argumentam que praticam a leitura das informações presentes no fórum.

Para tal, é de extrema valia o recebimento de sugestões por partes dos professores e alunos, a fim escutar e tentar entender as necessidades de acordo com a análise dos resultados. O feedback é um instrumento poderoso para estabelecer caminhos para modificação de cenários mais positivos a partir de uma realidade já conhecida. De posse desse entendimento separamos nos dois questionários uma questão aberta "subjetiva", com a seguinte indagação: Que sugestões de implementação e melhorias na Ferramenta Fórum, você daria? Assim, com o intuito de receber e escutar sugestões e/ou respostas que não foram contempladas nas questões anteriores. Dessa forma, obtivemos as seguintes respostas:

Tabela 1. Sugestões de professores e alunos para melhorias no Fórum

\begin{tabular}{|l|l|}
\hline \multicolumn{1}{|c|}{ PROFESSORES } & \multicolumn{1}{|c|}{ ALUNOS } \\
\hline $\begin{array}{l}\text { Sugiro a implementação de recursos mais } \\
\text { avançados, como por exemplo, ferramentas de } \\
\text { áudio e chamadas de vídeo para estabelecer } \\
\text { multi-conferências entre os participantes da turma. }\end{array}$ & $\begin{array}{l}\text { Grupos de alunos para que a interação on LINE } \\
\text { fosse efetiva. 6-10 estudantes e um tutor discutindo } \\
\text { sobre o tema. Os fóruns chegam até cem } \\
\text { postagens, não há como acompanhar. }\end{array}$ \\
\hline $\begin{array}{l}\text { Melhorar o visual e as ferramentas de edição, para } \\
\text { as áreas tecnológicas temos muitas dificuldades, } \\
\text { por exemplo desenhar estruturas químicas } \\
\text { tridimensionais, escrever reações químicas... }\end{array}$ & Ser criativo e diferente \\
\hline $\begin{array}{l}\text { Envio de vídeos e áudios. Alerta de resposta direta } \\
\text { ao interessado. }\end{array}$ & Criação de vídeos \\
\hline $\begin{array}{l}\text { Desenvolver uma ferramenta objetiva, que permita } \\
\text { a avaliação da participação efetiva do aluno no } \\
\text { fórum . Do modo como está, o aluno às vezes } \\
\text { participa só com um "oi " ou texto semelhante o } \\
\text { que toma tempo de leitura e não gera discussão. Se } \\
\text { o fórum for organizado de modo a recuperar a aula } \\
\text { ou um roteiro para que o aluno possa construir o } \\
\text { conhecimento será bem interessante. }\end{array}$ & $\begin{array}{l}\text { Que eu pudesse olhar as respostas dos colegas } \\
\text { voltar à página anterior e depois clicar no nome do atumo olhar as respostas dos colegas. } \\
\text { nãor isso }\end{array}$ \\
\hline $\begin{array}{l}\text { Sugiro a implementação de recursos mais } \\
\text { avançados, como por exemplo, ferramentas de } \\
\text { audio e chamadas de vídeo para estabelecer }\end{array}$ & $\begin{array}{l}\text { Acho que a proposta de gamificação, de interação } \\
\text { ou outra configuração podem ajudar na dinâmica } \\
\text { da ferramenta fórum na educação à distância }\end{array}$ \\
\hline
\end{tabular}


multi-conferências entre os participantes da turma.

Os relatos dos professores e alunos, apontam para possíveis ações que fomentem e ressignifique o uso do fórum como ferramenta que potencializa a colaboração, interação e aprendizagem. Tais sugestões, evidenciam o desejo de um espaço virtual mais dinâmico, motivador, objetivo e interativo. Além de assinalar para mudanças que tornem o uso do fórum, um modo possível de otimização do processo da condução da aprendizagem e de sua validação.

\section{Conclusões}

Ao término desse trabalho, observam-se as contribuições da utilização da ferramenta fórum para promover colaboração na $\mathrm{EaD}$, sobretudo, no processo de ensino e aprendizagem, viabilizando permite diversas possibilidades de interação na promoção do conhecimento. Porém, ainda pouco utilizada em sua devida potencialidade.

Esperamos que as inquietações reveladas na pesquisa, bem como o referencial teórico, apresentado neste trabalho represente um ponto de partida para possíveis reflexões e consequentemente transformações para o uso do fórum como ferramenta colaborativa. Assim, permitindo aos professores e tutores frente ao uso das funcionalidades do ambientes virtuais de aprendizagem, especialmente, o fórum, e aperfeiçoando o seu papel de mediador na utilização deste recurso, mas sempre com cuidado em realizar um bom planejamento das ações das atividades aplicadas, não interferindo muito para que os recursos tecnológicos não percam a sua essência e o seu caráter de facilitador na aprendizagem de um determinado conteúdo. Portanto, contribuindo no objetivo de melhorar o uso do fórum no ensino da atual na EaD e aproximar cada vez mais o aluno do objeto de conhecimento.

Ressalta-se que concepções, conceitos e questionamentos, ora apresentados no desenvolvimento desse objeto de estudo precisam ser aprofundados, pois não se esgotar apenas nesta pesquisa. Este trabalho, ao buscar investigar e compreender as contribuições sobre o tema abordado, esboça-se em apenas um recorte da realidade sobre o uso do fórum, necessitando aprofundamento em estudos posteriores, para conhecer motivos e aspectos causadores e/ou modificadores da realidade atual.

\section{Referências}


VII Congresso Brasileiro de Informática na Educação (CBIE 2018)

Anais do XXIV Workshop de Informática na Escola (WIE 2018)

ALMEIDA, M. E. B. de; VALENTE, J. A. Tecnologias e currículo: trajetórias convergentes ou divergentes? São Paulo: Paulus, 2011 - (Coleção Questões Fundamentais da Educação - 10).

COSTA, K. S; FARIA, G. G. EAD - Sua Origem Histórica, Evolução e Atualidade Brasileira Face ao Paradigma da Educação Presencial. In: Congresso Internacional ABED de Educação a Distância, 14, Santos, 2008. 10p. Disponível em: < http://www.abed.org.br/congresso2008/tc/552008104927AM.pdf $>$. Acesso em 25 mai. 2018.

GAGNE, Robert. The Condition of Learning and Theory of Instruction. Wadsworth Pub Co, $4^{\text {a }}$ ed. 1985

GIL, A. Carlos. Como Elaborar Projetos de Pesquisa. 4. ed. São Paulo: Atlas, 2002.

MALHOTRA, N. Pesquisa de marketing. 3.ed. Porto Alegre: Bookman, 2001.

MAYER, Richard. The Cambridge handbook of Multimedia Learning. New York: Cambridge University Press

PAULA, L. T. Informação em Ambientes Virtuais de Aprendizado (Ava). 2009. 148 f. Dissertação (Mestrado) - Programa de Pós-Graduação em Ciência da Informação, Escola de Ciência da Informação, Universidade Federal de Minas Gerais, 2009. Disponível em: $<$ http://www.bibliotecadigital.ufmg.br/dspace/bitstream/handle/1843/ECID-7X9JFD/di sserta.pdf;jsessionid=FAA0D804F677332ADB43A9ADD768C108? sequence $=1>$. Acesso em 30 Mar 2018.

RABELO, D.S.S. et al.; Utilização de técnicas de mineração de dados educacionais para predição de desempenho de alunos de $\mathrm{EaD}$ em ambientes virtuais de aprendizagem. Anais do Simpósio Brasileiro de Informática na Educação (SBIE), Recife-PE, 2017

SOARES, N. et al.; Inovações Tecnológicas em Escolas Públicas: Análise de Fatores Motivadores. Anais do XXII Workshop de Informática na Escola (WIE), Uberlândia-MG, 2016.

SCHLEMER, Eliane e GARRIDO, Susane. Unisinos Virtual: a construção de um futuro muito presente na educação online. Revista Colabor@ da CVA-RICESU, p.165-191, set. 2009.

STAHAL, G; KOSHMAN, T. e SUTHERS, D (2006). "Computer-supported collaborative learning: an historical perspective". In: R.K. Sawyer (Ed), Cambridge handbook of the learning sciences (pg.409-426). Cambridge, UK: Cambridge University Press, http://gerrystahl.net/cscl/CSCL_English.pdf in portuguese. Acesso em 30 Mar 2018. 